\title{
Fatigue strength of PBF-LB/M and wrought 316L stainless steel: effect of post-treatment and cyclic mean stress
}

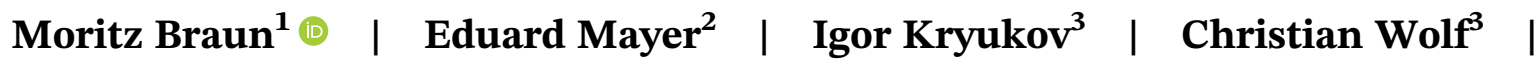

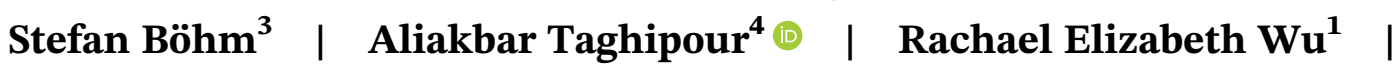 \\ Sören Ehlers ${ }^{1}$ (D) | Shahram Sheikhi ${ }^{2}$
}

${ }^{1}$ Institute for Ship Structural Design and Analysis, Hamburg University of Technology, Hamburg, Germany

${ }^{2}$ Institute of Materials Science and Joining Technology, University of Applied Science Hamburg, Hamburg, Germany

${ }^{3}$ Institute for Production Technologies and Logistics, Department for Cutting and Joining Manufacturing Processes,

University of Kassel, Kassel, Germany

${ }^{4}$ Department of Mechanical Engineering, Isfahan University of Technology, Isfahan, Iran

\section{Correspondence}

Moritz Braun, Institute for Ship Structural Design and Analysis, Hamburg University of Technology, Am Schwarzenberg Campus 4(C), Hamburg D-21073, Germany.

Email: moritz.br@tuhh.de

\begin{abstract}
Additive manufacturing (AM) enables the cost-effective production of complex components, many of which are traditionally manufactured using costly subtractive processes. During laser-based powder bed fusion of metals (PBF-LB/M), internal pores and rough surfaces are typically inevitable, reducing fatigue and corrosion resistance compared to traditional processes. Additionally, large defects often occur near to or at surfaces. Thus, this study investigates the effect of hybrid additive and subtractive manufacturing on the fatigue strength of AISI 316L. To this goal, different post-treatment routes are compared with wrought material. Additionally, computed tomography is used to determine the necessary machining depth of the surface layer. In this study, heat treatment and machining are both found to significantly increase fatigue strength (17\% and $87 \%$ ). Finally, the mean stress sensitivity $M$ of as-built $\mathrm{PBF}-\mathrm{LB} / \mathrm{M}$ and wrought material is found to be highly affected by the assessed number of cycles to failure and residual stresses in PBF-LB/M material.
\end{abstract}

\section{K E Y W O R D S}

additive materials, heat treatment, mean stress effects, selective laser melting, surface roughness, surface treatment

\section{1 | INTRODUCTION}

Additive manufacturing (AM) is a rapidly developing technology that combines computer-aided design with material processing and shaping to produce structures with complex geometry. AM is particularly suitable for low-volume components, tailor-made, and valuable products. $^{1}$ Laser-based powder bed fusion of metals (PBF-LB/M) also known as direct metal laser melting (DMLM) or selective laser melting (SLM), a form of $\mathrm{AM}$, has recently experienced rapid industrialization and popularity and is now the most widely used process for manufacturing using metal powders. ${ }^{2}$ This process employs a building platform, onto which thin layers of powder are applied. A laser beam selectively fuses the particles ("scanning") before the platform is lowered to add another thin layer of powder; this process is repeated until the whole model is complete. ${ }^{3}$ This form of manufacturing is "additive," as each layer builds on the last, enabling lightweight structures with complex geometry-which would require costly methods such as casting, welding, and machining in 
conventional processes. ${ }^{4}$ At a time when resource use is already a priority, emphasis on AM can be expected to rise significantly in the future. Questions surrounding the mechanical properties of novel manufacturing processes, compared to traditional manufacturing methods, are already emerging. In this context, cyclical material and component properties are of particular importance. While the fatigue strength of components manufactured by machining processes correlates directly with the tensile strength of the material, it is also influenced by production-related pores and defects (such as nonfused powder) in comparable AM components. Figure 1 shows the results of a computed tomography (CT) scan of an PBF-LB/M specimen with an increase in surface roughness due to partially nonfused powder and irregular melt pool surfaces (A) and embedded pores (B).

The application readiness of components used in the many industries is not only defined by their fatigue strength related to inner defects and surface quality but often by their corrosion resistance as well. For example, in order to withstand strong corrosive environment associated with the application in the offshore industry, a high surface quality is required. As-built AM parts produced by PBF-LB/M rarely meet this standard and, coupled with near-surface defects, often have low corrosion resistance compared to traditionally produced components. ${ }^{6,7}$ Thus, hybrid additive and subtractive AM methods that combine AM processes with subtractive processing techniques such as milling, grinding, and turning offer a possibility to increase fatigue strength but also corrosion resistance.
Such a process is schematically presented in Figure 2; nonetheless, this technology is relatively new, and there are knowledge gaps due to limited in-practice use on process planning and monitoring, removal of powder, and so on. ${ }^{8}$

The effect of various postprocessing techniques on fatigue strength of AM parts-including marine grade steels such as $316 \mathrm{~L}$ - has been investigated in the past; however, to the best knowledge of the authors, thorough investigation of static and cyclic material properties resulting from different postprocessing routes, including a comparison with wrought material, has not been reported yet. Hence, this study investigates the fatigue strength of different postprocessing methods and the effect of cyclic mean stresses on PBF-LB/M and wrought 316L specimens. To this goal, the following aspects are investigated and presented:

- PBF-LB/M and wrought material 316L are characterized by fatigue and tensile tests, as well as by CT scans, scanning electron microscope fractography, and a microstructure comparison.

- The effect of various influencing factors on fatigue strength is assessed, for example, surface condition, defects, and residual stress.

- The effect of cyclic mean stress is assessed by establishing Haigh diagrams for as-built and wrought material 316L.

The following section will offer a short overview of current state-of-the-art research on the fatigue

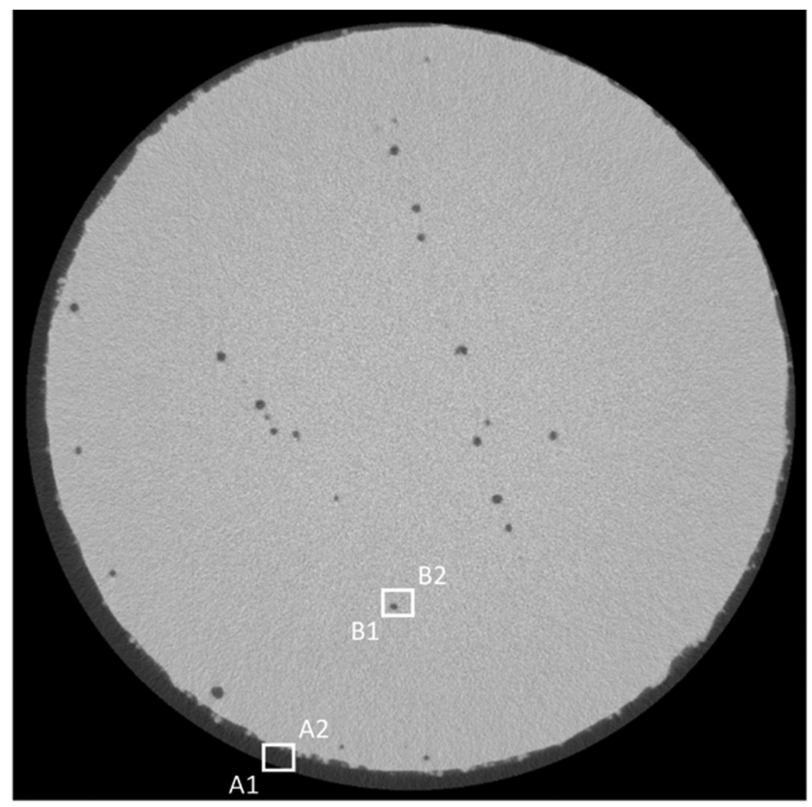

0.0 $2.5 \mathrm{~mm}$

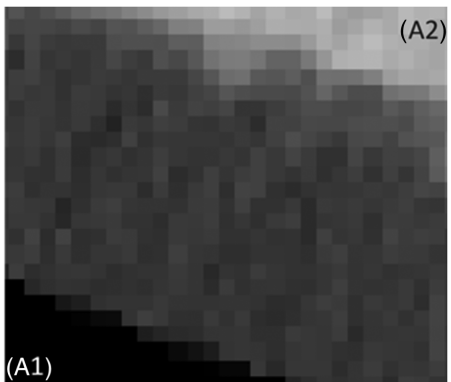

(B2)

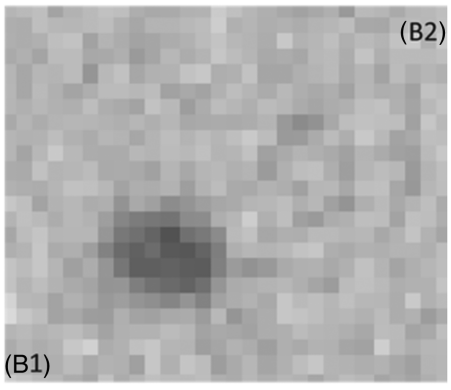

0.0 0.05 $0.1 \mathrm{~mm}$
FI GURE 1 CT scan of a 316L sample produced by PBF$\mathrm{LB} / \mathrm{M}$ with magnifications of the surface roughness (A1-A2) and a pore (B1-B2); taken from Braun et al. ${ }^{5}$ 
1. Powder distribution

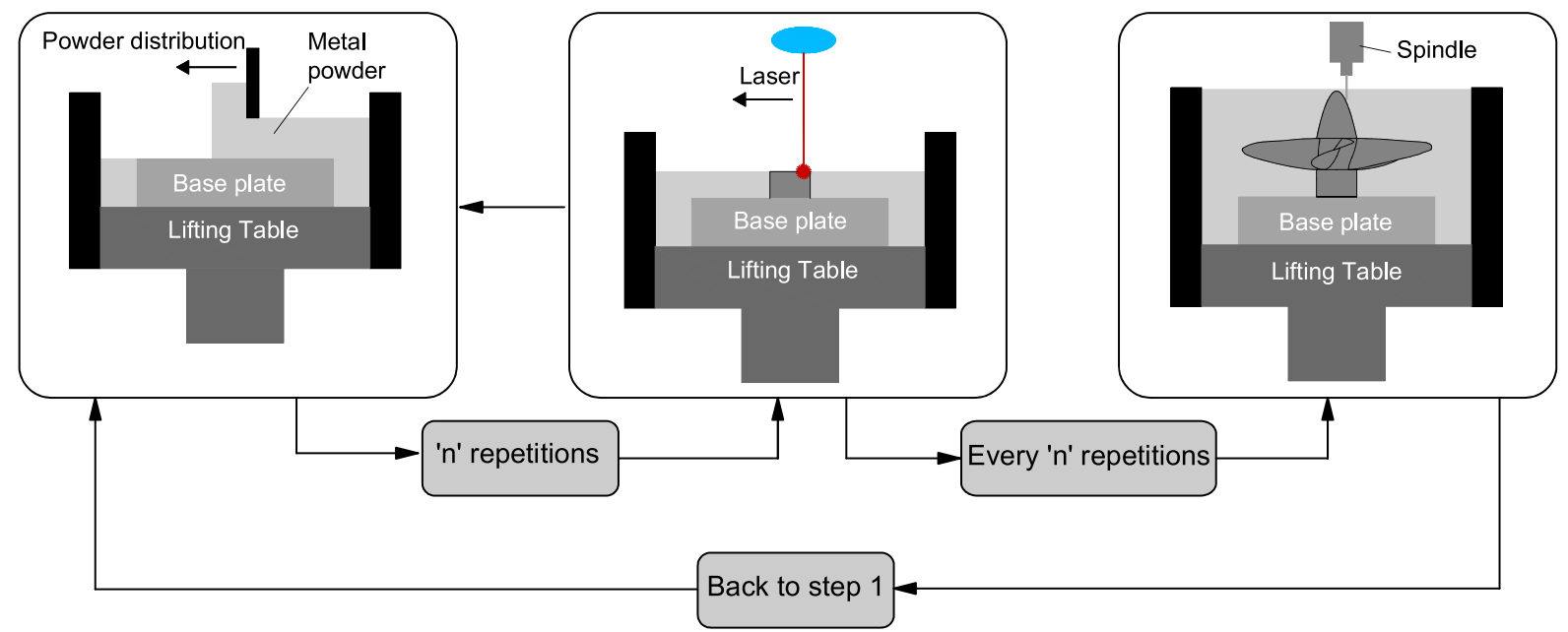

F I G U R E 2 Schematic illustration of a hybrid workflow combining additive and subtractive manufacturing processes; based on Cortina et al. ${ }^{8}$ [Colour figure can be viewed at wileyonlinelibrary.com]

strength of AM components and post-treatment processes, followed by an investigation on the fatigue strength of AM samples made of austenitic stainless steel 316L. Finally, a comparison of fatigue strength and mean stress sensitivity for the different processing techniques is performed and verified by literature results.

\section{2 | FATIGUE STRENGTH OF ADDITIVELY MANUFACTURED COMPONENTS}

\section{1 | Effect of pores and other production defects}

While the notch acuity is usually decisive for the fatigue resistance of notched components, cracks often occur at internal irregularities such as pores or inclusions in AM parts-especially, when the surfaces are smooth. The influence of pores and other defects such as blowholes on the fatigue strength of cast or sintered components is well-known (cf. Garb et al. and Shirani and Härkegård $\left.{ }^{9,10}\right)$. In components manufactured using PBF$\mathrm{LB} / \mathrm{M}$, lower porosity and thus higher density lead to fewer brittle fractures in the crack path and overall to a longer service life. In contrast, higher density may create secondary cracks at micropores and inclusions, which are often stopped at microscopic barriers. ${ }^{11}$ Depending on the shape, size, and location of the defects in the component, these can lead to a strong increase in local stress and thus to a significant reduction in fatigue strength Defects close to the surface are often particularly critical, as they lead to surface cracks that propagate faster than embedded cracks. In the PBF-LB/M process, the defect density is often highest in the surface layer and decreases towards the center of the component, since this contour is produced first and at a higher scanning speed., . $^{32,13}$ Nonfused powder residues are particularly prone to accumulate on the surface layer; however, slower scanning speeds increase production time significantly and might even lead to keyhole porosities. ${ }^{14}$ Post-treatment of the surface layer of AM components is therefore an obvious step to increase the fatigue strength. This will be discussed below using the example of austenitic stainless steel 316L.

\subsection{Effect of post-treatment routes}

AISI 316L (X2CrNiMo17-12-2, 1.4404) is an austenitic material with excellent mechanical properties, high corrosion resistance due to the high chromium and low carbon content, and additional resistance to pitting due to the high molybdenum content. This steel is characterized by excellent weldability and cold formability. Machining is difficult as the high strength leads to rapid wear of tools. Consequently for 316L, AM processes represent a cost-effective alternative to classical; however, AM components typically have different mechanical properties than components produced by traditional processes. 
In a study with samples with low and high porosity, Zerbst and Hilgenberg ${ }^{15}$ compared AM parts to semifinished products made of $316 \mathrm{~L}$, observing higher stiffness and low fracture strain of PBF-LB/M specimens. Similar stress-strain curves were only obtained after subsequent annealing of the PBF-LB/M specimens. Furthermore, the layer thickness of the AM process has significant influence on the mechanical properties. Layer thicknesses above $75 \mu \mathrm{m}$ lead to a significant reduction in strength and ductility in the vertical built direction but an increase in ductility in other horizontal directions ${ }^{16}$; this is due to different porosity, resulting from changed layer thickness. In contrast to semi-finished products, components manufactured with PBF-LB/M suffer from pores and other defects, as well as high surface roughness and tensile residual stresses. Depending on the expected load cycles the component is subjected to, it is advisable to carry out post-treatment to ensure sufficient fatigue strength.

The possibilities for improving the fatigue strength of additive materials include surface treatment, tensile stress reducing or compressive stress inducing processes, and processes that close existing defects and pores. Due to the PBF-LB/M process, high residual stresses are particularly prone to occurring in the surface layer. ${ }^{17}$ These may be modified using heat treatments, including heating the base plate during production, surface refinement by rescanning or remelting the surface, or hot isostatic pressing (HIP). ${ }^{15}$ During the HIP process, the material is simultaneously exposed to a very high temperature (usually above $1000^{\circ} \mathrm{C}$ ) and a high pressure in order to change the microstructure and close possible pores and defects. Furthermore, it was found that HIP also reduces the surface roughness. ${ }^{18}$ In several studies, a significant increase in the fatigue strength of additively manufactured samples made of Ti-6Al-4V alloys was found ${ }^{4,19}$; however, other studies also suggest that higher fatigue strength can be achieved by specific heat treatment. ${ }^{20}$ For stainless steels, however, HIP seems to lead to a reduction in fatigue strength, especially in the lowcycle fatigue range. ${ }^{21,22}$ Leuders et al. ${ }^{22}$ have found a significant reduction in fatigue strength post HIP treatment at $1150^{\circ} \mathrm{C}$ and a pressure of 1000 bar compared to a heat treatment at $650^{\circ} \mathrm{C}$ and the as-built condition. On the other hand, the high-cycle fatigue strength was increased by HIP treatment. This is supported by another study from Riemer et al. ${ }^{23}$ who observed a significant increase in the crack growth threshold for HIP-treated samples. One major drawback of HIP treatment of PBF-LB/M stainless steel seems to be a reduction in corrosion resistance. ${ }^{24}$ In conclusion, a final assessment of the influence of HIP on the fatigue strength of stainless steels produced by $\mathrm{AM}$ is not yet possible; however, there are several other methods that enable an improvement of fatigue strength of stainless steels parts made by PBF-LB/M.

Contrary to HIP treatment, heat treatment will induce grain coarsening and homogenization by recrystallization, which can improve the crack initiation behavior of PBF-LB/M components made of stainless steels. $^{20,21}$ This is exacerbated by the reduction of tensile residual stresses, which otherwise have a negative effect on fatigue strength. ${ }^{23}$ For low temperatures up to $480^{\circ} \mathrm{C}$, this does not seem to affect the microstructure and fatigue strength of 316L. ${ }^{20} \mathrm{In}$ a number of other investigations, changes in mechanical properties were only detected after heat treatment at temperatures above $600^{\circ} \mathrm{C}^{25-27}$ Heat treatment with temperatures in the range $600-650^{\circ} \mathrm{C}$ resulted in almost identical tensile strength properties with significantly reduced fracture strain but increased microhardness. ${ }^{25-27}$ On the other hand, heat treatment at these temperatures does not seem to affect fatigue crack propagation significantly. ${ }^{23,28}$ Changes in fatigue strength are consequently related to changes in fatigue crack initiation behavior. The critical heat treatment temperature at which recrystallization begins and a homogeneous microstructure of PBF-LB/M $316 \mathrm{~L}$ is formed was determined to be $850^{\circ} \mathrm{C} .{ }^{27}$ For higher temperatures, both porosity and hardness decrease significantly. Furthermore, heat treatment of 316L also increases the corrosion resistance. ${ }^{29}$

The aim of surface post-treatment processes is similar to that of welded components, namely, to reduce processrelated notches, which reduce the fatigue strength. The effect of surface treatment has been extensively proven for various materials; see previous studies, ${ }^{19,21,30-34}$ and recent research suggests that the fatigue strength significantly increases by surface treatment to the level of wrought material. ${ }^{34,35}$ Sarkar et al. ${ }^{32}$ for example, examined the influence of different surface finishing processes using the example of the corrosion-resistant steel 15-5 $\mathrm{PH}$. By electropolishing the surface, fatigue strength increased by approximately $100 \%$. The highest fatigue strength of $120 \%$ was achieved with surface refinement by rescanning the surface.

An alternative to improve the surface of additively manufactured components is machining of surfaces. This type of hybrid machining is particularly suitable for targeted use in highly stressed areas of AM components or on components such as turbine blades, which have hydrodynamic requirements for a smooth surface. Compared to HIP and incorrectly executed heat treatment, no disadvantages exist besides the removal of some additional material. Furthermore, hybrid processes enable extensive possibilities for topology optimization. ${ }^{36}$

In this study, three different processing states are investigated and compared with specimens obtained from 
wrought material. The different states are (1) as-built, (2) heat-treated, and (3) machined and heat-treated.

\section{3 | MATERIALS AND METHODS}

\section{1 | Specimen preparation}

In the subsequent section, the material and test methods are introduced which are applied to assess the fatigue strength of $316 \mathrm{~L}$ using different $\mathrm{PBF}-\mathrm{LB} / \mathrm{M}$ processing routes in comparison with wrought material. For this purpose, a standard specimen geometry (see Figure 3) was selected for the fatigue tests, following ASTM E466- $15^{37}$ with a stress concentration factor $K_{t}=1.05$. The stress concentration was chosen to be small to limit the effect on bulk material properties. It was determined from stress concentration factor charts by Pilkey and Pilkey. ${ }^{38}$

Several specimens were manufactured with an excess of $1 \mathrm{~mm}$ on all surfaces, which was later removed by machining to ensure all specimens had the same final dimension. All specimens were manufactured together to achieve conservative results as the production of several components usually results in a less favorable microstructure and poorer mechanical properties. ${ }^{39}$ The specimens were produced in a Renishaw AM250 PBF-LB/M machine. The chemical composition of the powder is listed in Table 1 and the process parameters in Table 2.

The machined specimens were then heat-treated together with a number of as-built specimens to investigate the effect of residual stresses. The samples were heat-treated at $650^{\circ} \mathrm{C}$ for $2 \mathrm{~h}$ and furnace cooled. The heat treatment was performed after machining as such processing induces residual compressive stresses in the surface layer, ${ }^{40}$ which would affect the comparison.

Figure 4 shows exemplary surfaces of both series. The machined specimens were not polished in order to achieve fatigue strength results representative for typical AM components not just unrealistically high fatigue strength. Hence, marks from the manufacturing process are still clearly visible on the machine specimens. For a comparison of surface roughness, three samples of heat-treated and machined specimens were measured. As the heat treatment temperature does not result in a change in microstructure, it is assumed that this state is also representative for the as-built specimens. The results of the measurement are shown in Table 3 . Machining reduces the arithmetic mean roughness $R_{a}$ by a factor of about 6 and the maximum roughness $R_{t}$ by a factor of 8 .

\section{2 | Microstructure and mechanical characterization}

As mentioned earlier, the majority of defects in AM components typically appear close to the surface. Thus, a micro-CT scan of an as-built specimen was performed to investigate the depth required to remove the majority of defects near the surface. The scan was performed using a Carl Zeiss X-ray microscope Xradia Versa 520 with a voxel size of about $4.1 \mu \mathrm{m}$. The result of the scan is presented in Figure 5, with each point corresponding to a pixel obtained from one picture. For the postprocessing

FIGURE 3 Specimen geometry according to ASTM $\mathrm{E} 466-15^{37}$

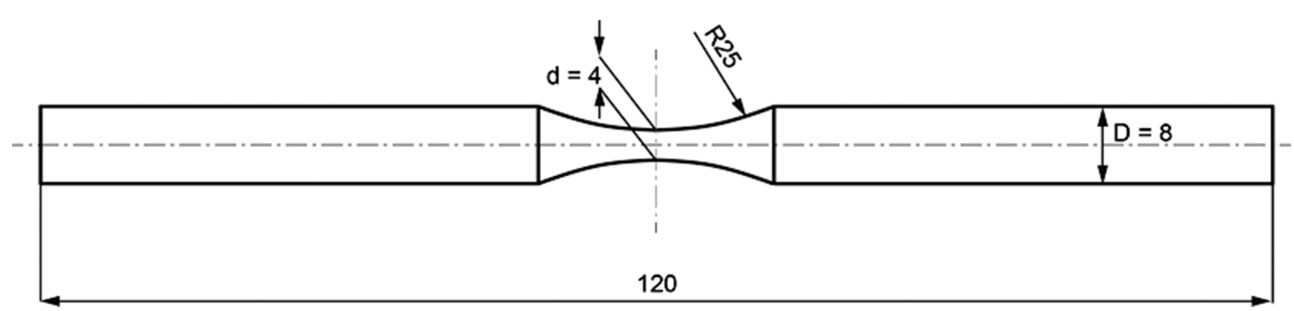

TABLE 1 Chemical composition of 316L used for fabrication of PBF-LB/M specimens

\begin{tabular}{lllllllll} 
& C & Mo & Ni & Ma & Cr & Si & O & Fe \\
Weight (\%) & 0.006 & 2.5 & 12.5 & 1.5 & 16.6 & 0.7 & 0.063 & Balanced \\
\hline
\end{tabular}

TA B LE 2 Process parameters used for fabrication of the PBF-LB/M 316L specimens

\begin{tabular}{llllll} 
Laser power & $\begin{array}{l}\text { Layer thickness } \\
(\boldsymbol{W})\end{array}$ & $\begin{array}{l}\text { Powder density } \\
\left(\mathbf{g} / \mathbf{c m}^{\mathbf{3}}\right)\end{array}$ & $\begin{array}{l}\text { Width of molten pool } \\
(\boldsymbol{\mu m})\end{array}$ & $\begin{array}{l}\text { Exposure time } \\
(\boldsymbol{\mu} \mathbf{s})\end{array}$ & $\begin{array}{l}\text { Scan line spacing } \\
(\boldsymbol{\mu m})\end{array}$ \\
\hline $100-180$ & 40 & 4.29 & 115 & 80 & 65 \\
\hline
\end{tabular}


(A)

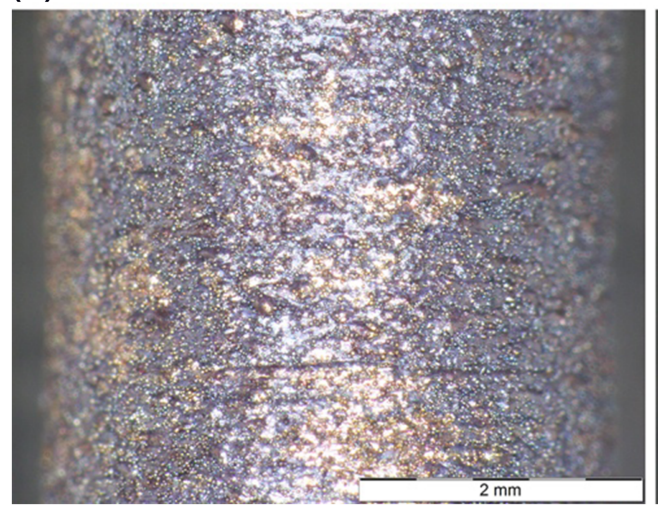

(B)

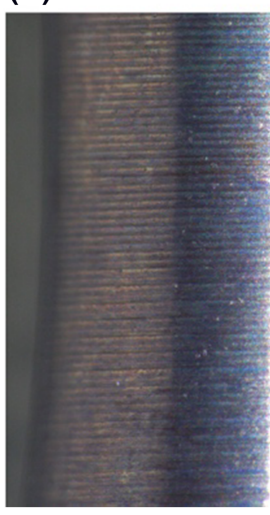

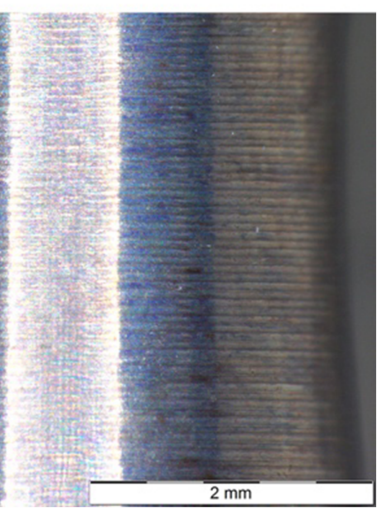

FIG URE 4 Microscopic images of the surface of the PBFLB/M 316L samples after heat treatment with the as-built surface (A) and after machining (B), from Braun et al. ${ }^{5}$ [Colour figure can be viewed at wileyonlinelibrary.com]
TABLE 3 Results of the roughness measurement ${ }^{5}$

\begin{tabular}{|c|c|c|}
\hline & $\begin{array}{l}\text { Heat- } \\
\text { treated }\end{array}$ & $\begin{array}{l}\text { Machined \& heat- } \\
\text { treated }\end{array}$ \\
\hline Maximum roughness $R_{t}$ & $\begin{array}{l}41.929 \\
\pm 0.065\end{array}$ & $5.062 \pm 0.063$ \\
\hline $\begin{array}{l}\text { Arithmetic mean } \\
\text { roughness } R_{a}\end{array}$ & $\begin{array}{l}6.295 \\
\pm 0.041\end{array}$ & $1.024 \pm 0.005$ \\
\hline
\end{tabular}

of the scan, a MATLAB tool was created that detects voxels without material and thereby finds defects and pores.

Once all pictures were assessed and the size of defects determined, all defects were projected on one plane to determine the thickness of the surface layer containing the majority of defects and to determine the statistical distribution of defects. The thickness of this layer is approximately $250 \mu \mathrm{m}$, and the area of the largest defect was $0.06 \mathrm{~mm}^{2}$. This means that machining of approximately four scan lines is required to sufficiently remove subsurface defects. The chosen machining depth of $1 \mathrm{~mm}$ is thus sufficient to remove defects close to the surface.

The relative frequency in volume and in the different planes is presented in Figure 6. As expected, the majority of defects are rather small. Interestingly, the planar area in $x-y$ direction is slightly smaller than for the others. This is related to defects with a larger dimension in vertical direction, which can also be seen in Figure 5A.

In addition to the micro-CT scan, micrographs of the PBF-LB/M 316L were produced ${ }^{41}$ and compared with micrographs of the wrought material. The wrought material shows a typical microstructure for rolled austenitic sheets after annealing. The typical twin formations can be seen in the polyhedral grains. The orientation of the grains, with an average grain size of about $30 \mu \mathrm{m}$, ensures quasi-isotropic properties of the component. In contrast, individual weld beads are clearly visible for the PBF-LB/M samples; see Figure 7.

This layered structure results from the segregation of alloy components in the very short solidification phase of the melt. In addition, the melt pool reacts with the atmosphere in the pressure chamber. Therefore, the melt pool boundaries become visible as a layer-like structure in the micrograph. The actual microstructure deviates from the typical austenitic microstructure of the wrought material. This epitaxial crystal growth leads to the formation of stem crystals, which continue to grow polyhedrically beyond the layer-like structure. As a result, the component exhibits anisotropic properties and has larger grains with an average grain size of about $200 \mu \mathrm{m}$.

Finally, the PBF-LB/M and wrought material were characterized by means of tensile testing. For this purpose, tensile test specimens with different orientation were manufactured and tested. ${ }^{41}$ The orientation of the specimens and the results are presented in Figure 8, where the graphs represent the mean stress-strain curves and the shaded area the standard deviation around the mean curve.

For each orientation, nine PBF-LB/M and three wrought material specimens were tested. The reason for the larger number of PBF-LB/M specimens was the expected higher scatter, which is evident from the test results. Interestingly, the stress-strain behavior of the wrought material is almost constant in and perpendicular to the rolling direction after yielding. Only the Young's modulus $E$ varies significantly with specimen direction. On the contrary, the building direction and the microstructure of the PBF-LB/M specimens have a major effect on the anisotropic static material behavior. The lowest yield and ultimate tensile strength, but highest fracture strain $\epsilon_{f}$, was observed in vertical building direction $(z x)$. The opposite is true for the $x y$ orientation. The $y z$ orientation is in between the others. While the PBF-LB/M specimens show a high yield to tensile strength ratio 
(A) Spatial distribution of pores

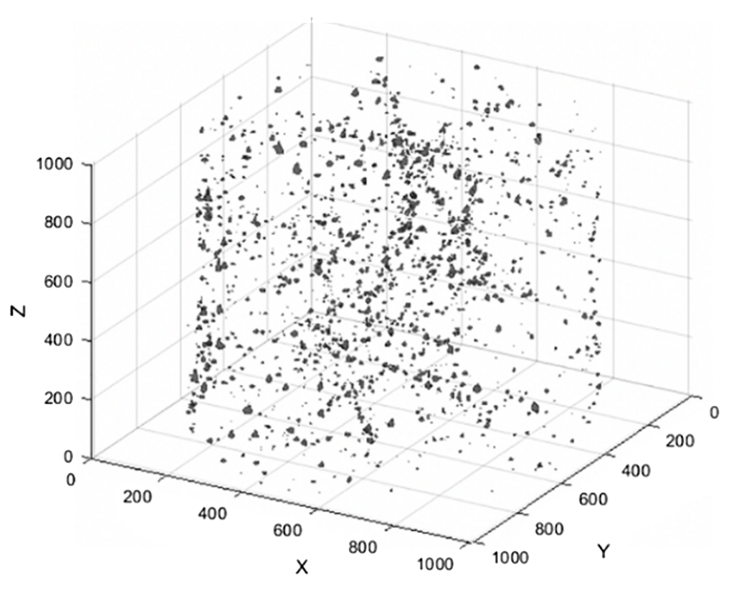

(B) Pores by volume - All $\left(\mathrm{mm}^{3}\right)$

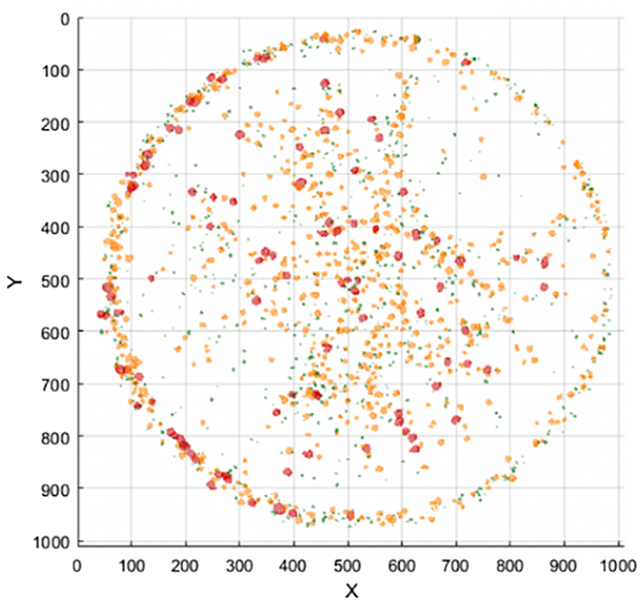

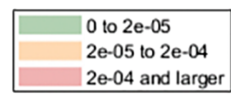

F I G U RE 5 Results of the CT scan of an PBF-LB/M 316L specimen (A) and projection of all detected defects on one plane to illustrate the accumulation of defects near free surfaces (B), axes units correspond to CT scan number and legend in $\mathrm{mm}^{35}$ [Colour figure can be viewed at wileyonlinelibrary.com]

(A)

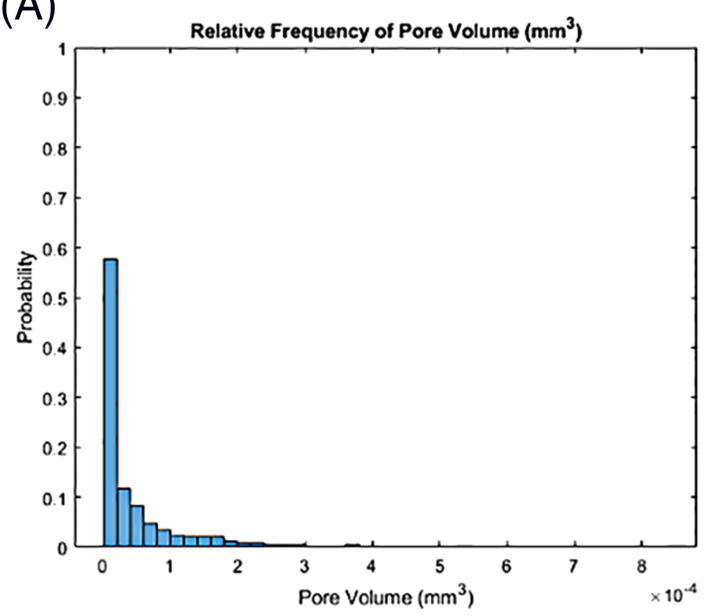

(C)

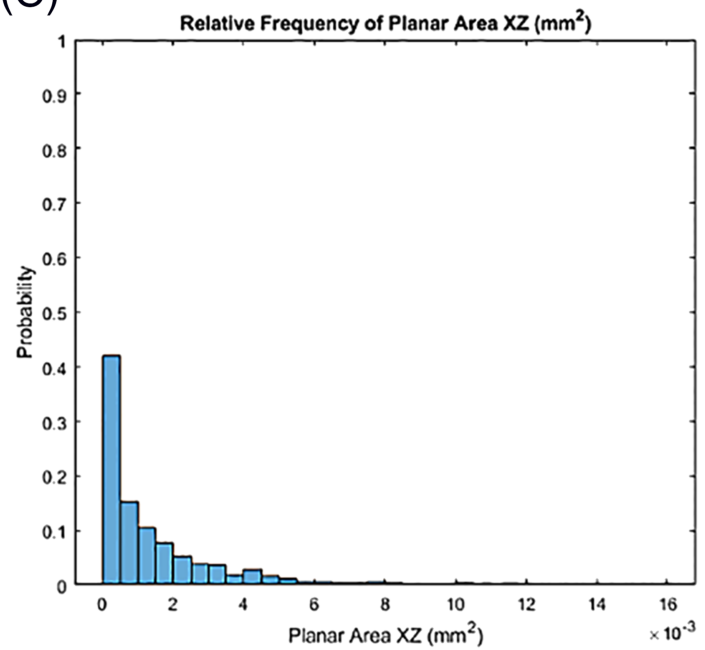

(B)

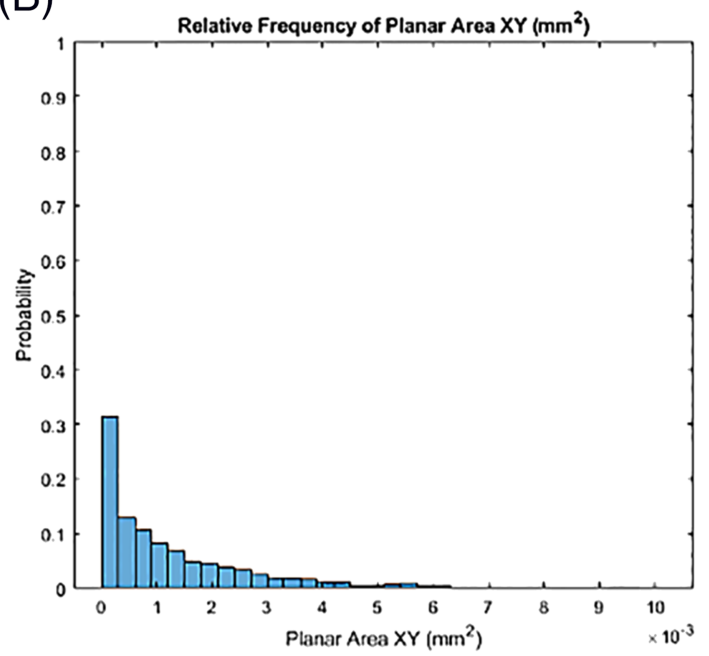

(D)

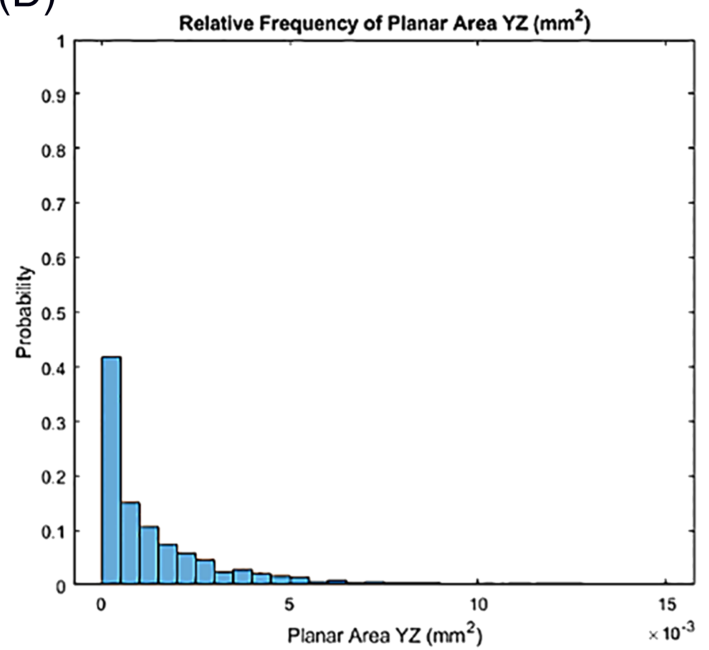

F I G U RE 6 Relative frequency of (A) pore volume, (B) planar area $X Y$, (C) planar area $X Z$, and (D) planar area $Y Z$ [Colour figure can be viewed at wileyonlinelibrary.com] 

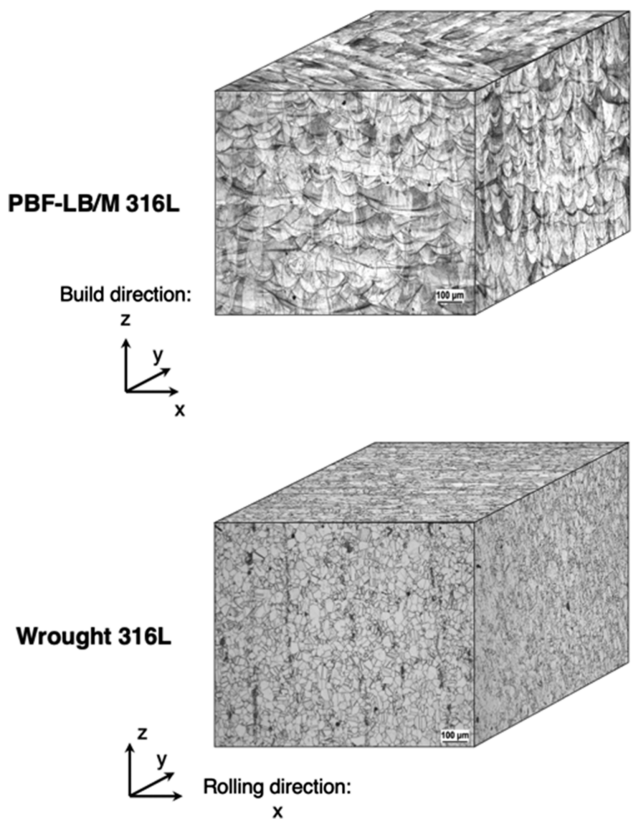
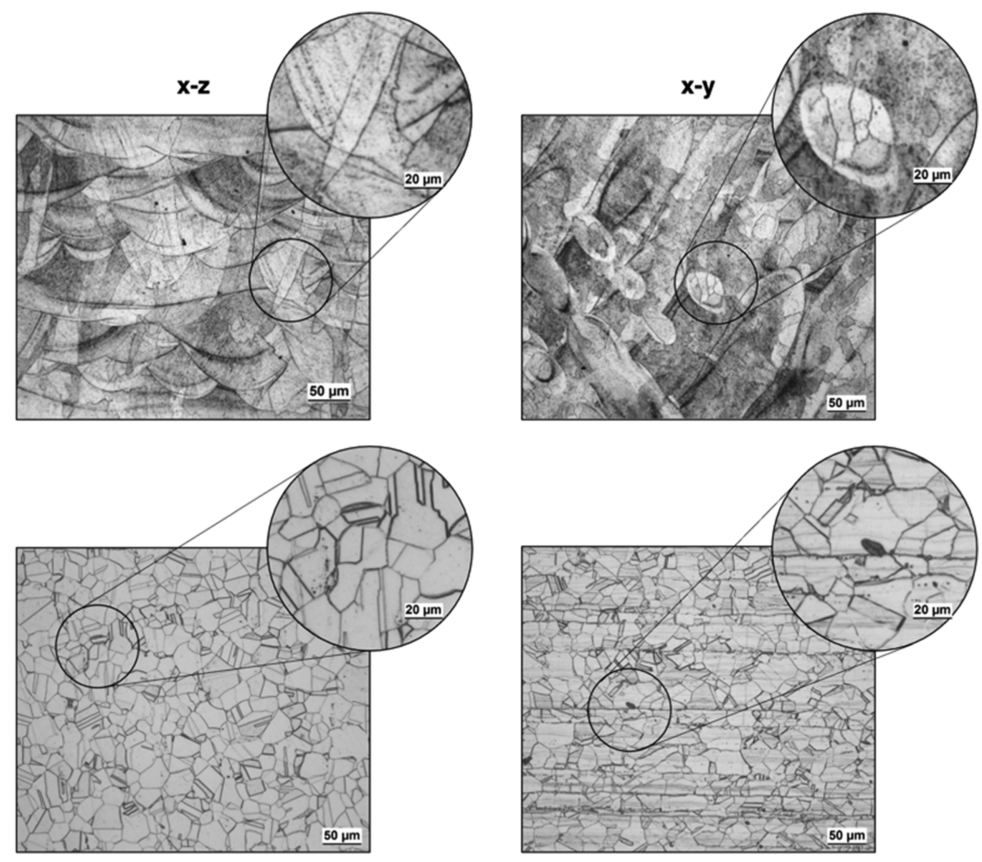

F I G U R E 7 Microstructure of PBF-LB/M and wrought 316L stainless steel with different planes $(x-y, x-z)$
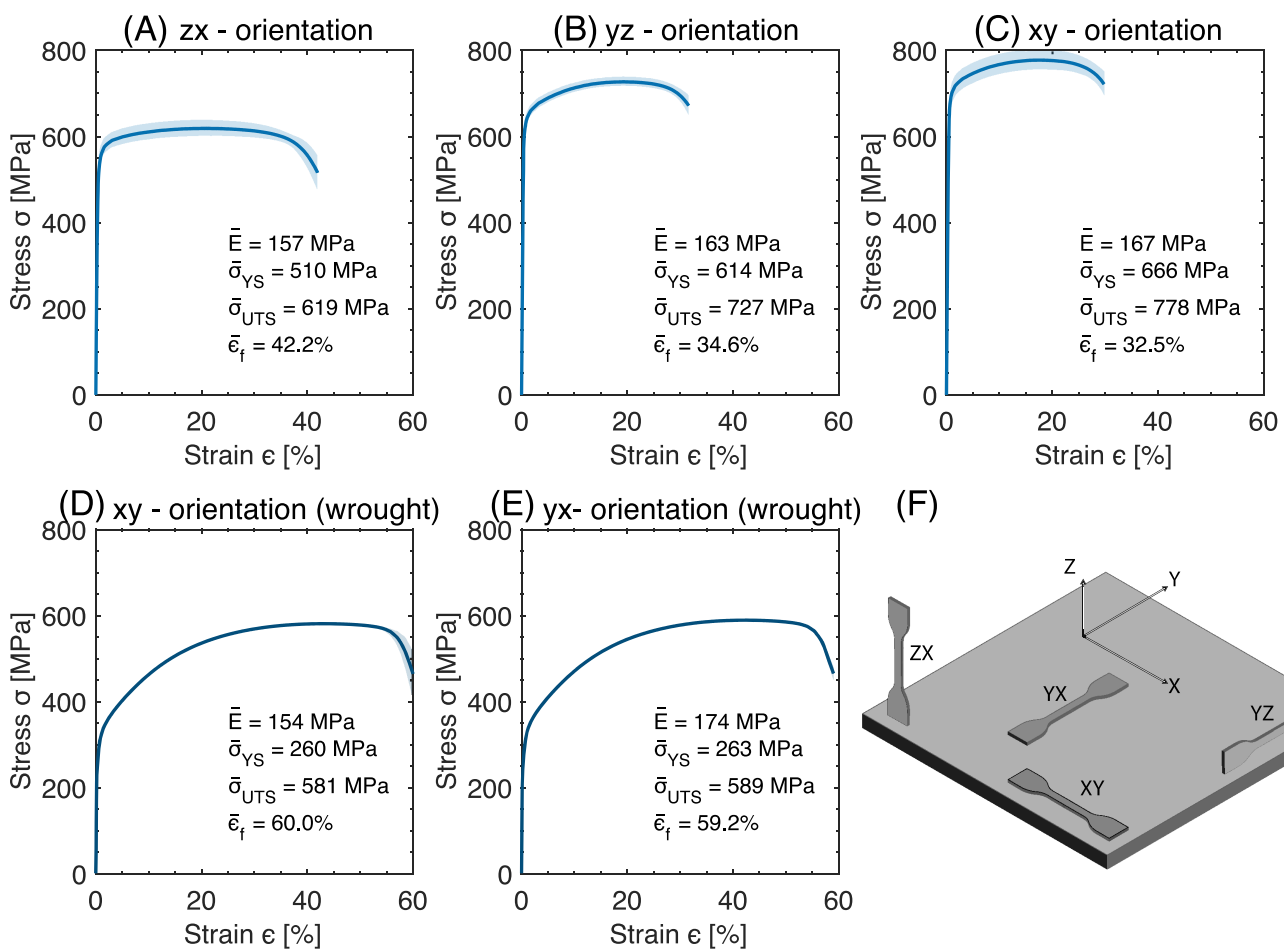

$(F)$

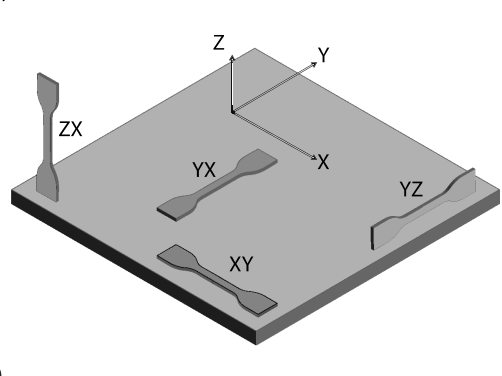

F I G U RE 8 Tensile test results of PBF-LB/M (A-C) and wrought (D-E) 316L steel with averages of measured strength parameters and schematic presentation of specimens' orientation (F) [Colour figure can be viewed at wileyonlinelibrary.com]

and lower ductility, the wrought material is characterized by a low yield strength and high fracture strain, which is typical for annealed $316 \mathrm{~L}$ plates; see previous studies. ${ }^{15,42-44}$ According to Elangeswaran et al., ${ }^{21}$ this can be related to the Hall-Petch relationship and to the difference in microstructure. While wrought $316 \mathrm{~L}$ 
exhibits coarse-grained austenitic microstructure, the high cooling rates during PBF-LB/M lead to a finegrained microstructure, cf. Figure 7.

\section{4 | FATIGUE TESTS OF WROUGHT AND PBF-LB/M SPECIMENS}

\section{1 | Experimental setup}

The fatigue tests of the wrought and PBF-LB/M specimens were carried out under force-controlled tension loading with a stress ratio $R=\sigma_{\min } / \sigma_{\max }=0$ and at a test frequency of $8 \mathrm{~Hz}$. Tests exceeding 2 million cycles were terminated and classified as run-outs (marked by arrows in Figure 8). The test evaluation was performed by linear regression with

$$
N=2 \times 10^{6}\left(\frac{\Delta \sigma_{n}}{\Delta \sigma_{R}}\right)^{-k}
$$

where $N$ is the endured number of cycles on the nominal stress range level $\Delta \sigma_{n}, \Delta \sigma_{R}$ is the reference fatigue strength at $2 \times 10^{6}$ cycles, and $k$ the free inverse slope.

\section{2 | Fatigue test results}

Besides the nominal stress results of each series, the results for mean $\Delta \sigma_{R, 50 \%}$ and mean minus two standard deviation fatigue strength $\Delta \sigma_{R, 97.7 \%}$ (survival probability of $P_{S}=97.7 \%$ ), the scatter range $T_{\sigma}$ between $2.3 \%$ and 97.7\% survival probability (shaded area), and the inverse slope $k$ are presented in Figure 9.

The comparison of the $S-N$ curves in Figure 10 clearly shows the influence of heat treatment and machining on the fatigue strength. Due to the reduction of residual stresses as a result of the heat treatment, the mean fatigue strength could be increased by $17.5 \%$ at $N=2 \times 10^{6}$ cycles. Unsurprisingly, machining leads to an even higher fatigue strength improvement. Here, both the mean fatigue strength and the fatigue strength corrected by twice the standard deviation are $120 \%$ higher than the results of the as-built specimens at $N=2 \times 10^{6}$ cycles. Moreover, the $S$ $N$ curves seem to converge towards the low-cycle fatigue regime. This is related to the fact that surface roughness has a significantly larger effect on fatigue strength reduction in the high-cycle fatigue regime compared to the lowcycle fatigue regime; see Radaj. ${ }^{45}$ More importantly, the fatigue strength of the machined PBF-LB/M specimens is on par with the wrought material. This confirms recent research results on post-treatment of AM components produced by PBF-LB/M; see Afkhami et al. and Solberg and Berto. ${ }^{34,35}$ Interestingly, the fatigue strength of the asbuilt PBF-LB/M specimens is about half of the wrought specimens, which clearly underlines the importance of post-treatment on critical areas of AM components.

While a large part of the fracture surface of the wrought specimen presented in Figure 11B is characterized by a shear lip due to plastic collapse, the fracture surface of the as-built specimen (Figure 11A) is showing fatigue crack propagation. In fact, two cracks initiated in this specimen (top left and bottom left). The crack propagation direction of all cracks, which is determined based on radial lines originating from the crack initiation location, is marked with arrows. Furthermore, magnifications of the fatigue cracks present the difference in fatigue crack initiation locations. The fatigue crack initiation in the wrought material specimen is related to microscopic inhomogeneities and the formation of ex- and intrusion at the material surface. On the contrary, the fatigue cracks that initiated in the as-built specimen are both related to large lack-of-fusion (LOF) defects at the surface of the specimen. Inside the LOF defect and along the surface, several partially melted particles can be seen.

In a study by Solberg et al. ${ }^{46}$ on PBF-LB/M 316L steel, a transition of failure location from surface near defects to internal defects was observed at high stress ranges; this was not the case in this study. All specimens including the machined specimens failed from defects at or close to the surface. This raises questions regarding how large the effect of process-induced defects on fatigue strength is in comparison with other influencing factors, that is, residual stresses and surface roughness. In order to quantify the effect of these influencing factors, an estimation of surface roughness effect is performed based on the FKM guideline $\mathrm{e}^{47}$ in the next section.

\section{3 | Estimation of fatigue strength reduction based on surface roughness}

The FKM guideline ${ }^{47}$ is typically used to design notched components produced by subtractive processes such as milling and turning. Thus, influencing factors such as material strength and temperatures can be assessed by means of empirical correction factors. Among those, the effect of surface roughness is assessed with respect to the ultimate tensile strength $R_{m}$ of the material; however, no actual correction function is given in the FKM guideline. ${ }^{47}$ In order to enable a direct calculation of the surface factor $K_{R, \sigma}$ for fatigue strength reduction, the data of the FKM guideline were extracted and curve fitted. The data and the resulting fit are presented in Figure 12 including the goodness-of-fit parameter $R^{2}$. 

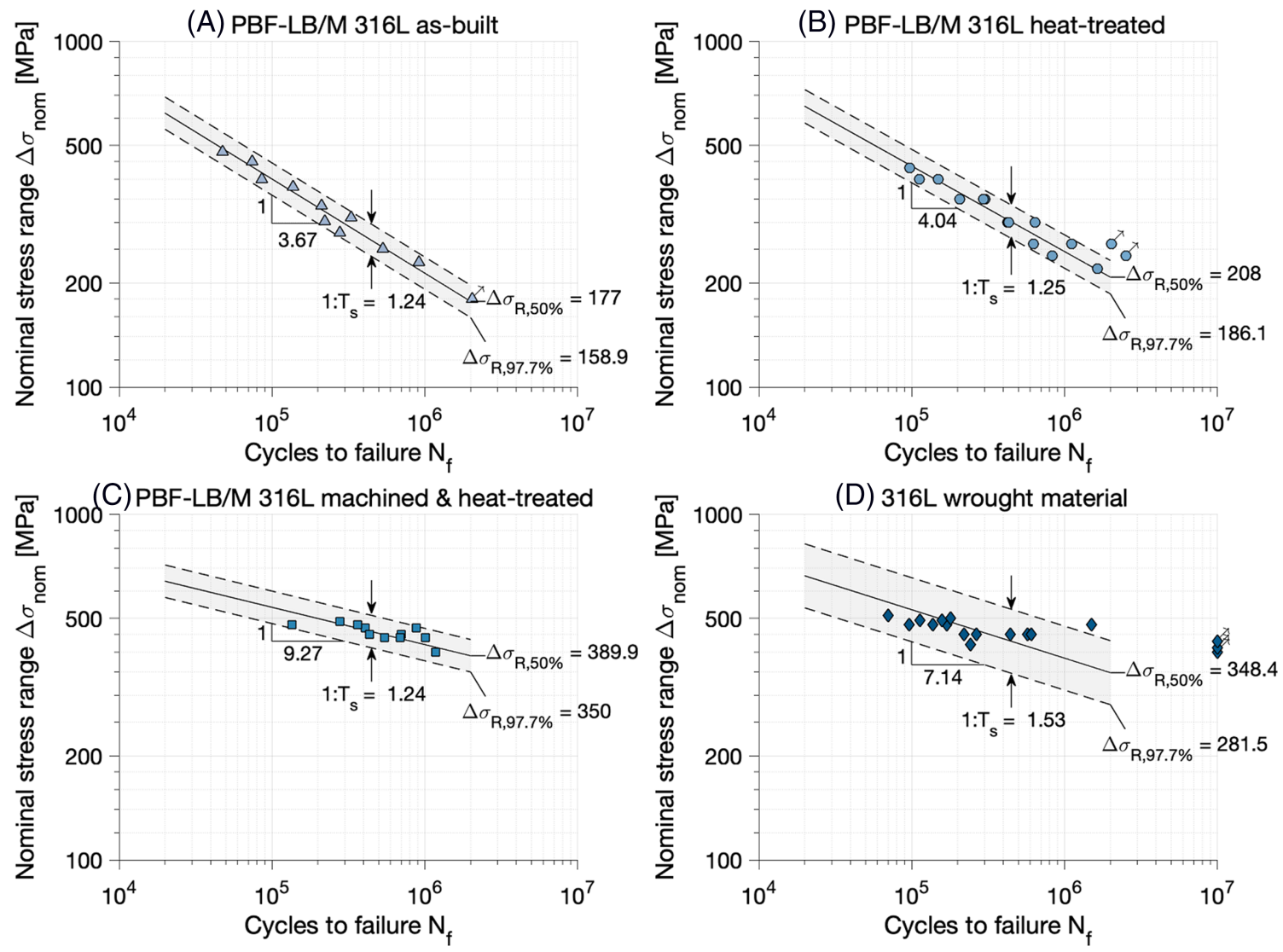

F I G U R E $9 S-N$ curves determined for different PBF-LB/M production routes (A-C) and for wrought material (D) at a nominal stress ratio of $R=0$ [Colour figure can be viewed at wileyonlinelibrary.com]

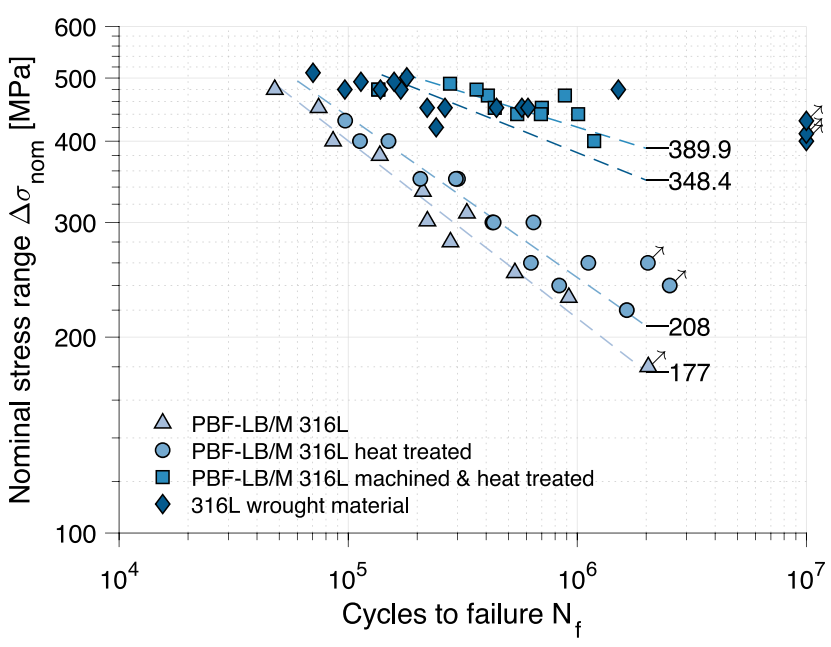

F I G U R E 10 Comparison of $S-N$ curves for different PBF$\mathrm{LB} / \mathrm{M}$ production routes with wrought material at a nominal stress ratio of $R=0$ [Colour figure can be viewed at wileyonlinelibrary. com]

Before the reduction factor is calculated, the measured arithmetic mean roughness $R_{a}$ is transformed into the maximum peak to valley height of five subprofiles $R_{z}$. New standards have discarded this measure for characterization of surface roughness ${ }^{48}$; however, it is still included for purposes of evaluating the effects of surface roughness based on FKM guideline. ${ }^{47}$ Based on the measured arithmetic mean roughness $R_{a}$ of both asbuilt and machined specimens, $R_{z}=25 \mu \mathrm{m}$ and $R_{z}=5 \mu \mathrm{m}$ for the as-built and machined surfaces are calculated, respectively.

If one compares the difference in the fatigue strength results with the reduction factors of the FKM guideline,${ }^{47}$ it becomes clear that the difference is not only due to the changed surface roughness. Using the functional relationship, a difference in fatigue strength of approximately $7.1 \%$ would be expected for the measured surface roughness difference. This agrees with an assessment recently performed by von Bock und Polach et al. ${ }^{49}$ on thermal cut edges with similar surface roughness. Interestingly, the estimated effect of surface roughness is lower than of residual stresses, which caused a difference in fatigue strength of $17.5 \%$; see Figure 10. Comparing the three influencing factors, it becomes clear that process-related defects have by far the highest effect on fatigue strength of PBF-LB/M components. 
F I G U R E 11 Scanning electron microscope fractography of as-built 316L PBF-LB/M specimen (A,C,E) and specimen obtained from wrought plate (B,D,F) with arrows marking the crack propagation direction [Colour figure can be viewed at wileyonlinelibrary. com]
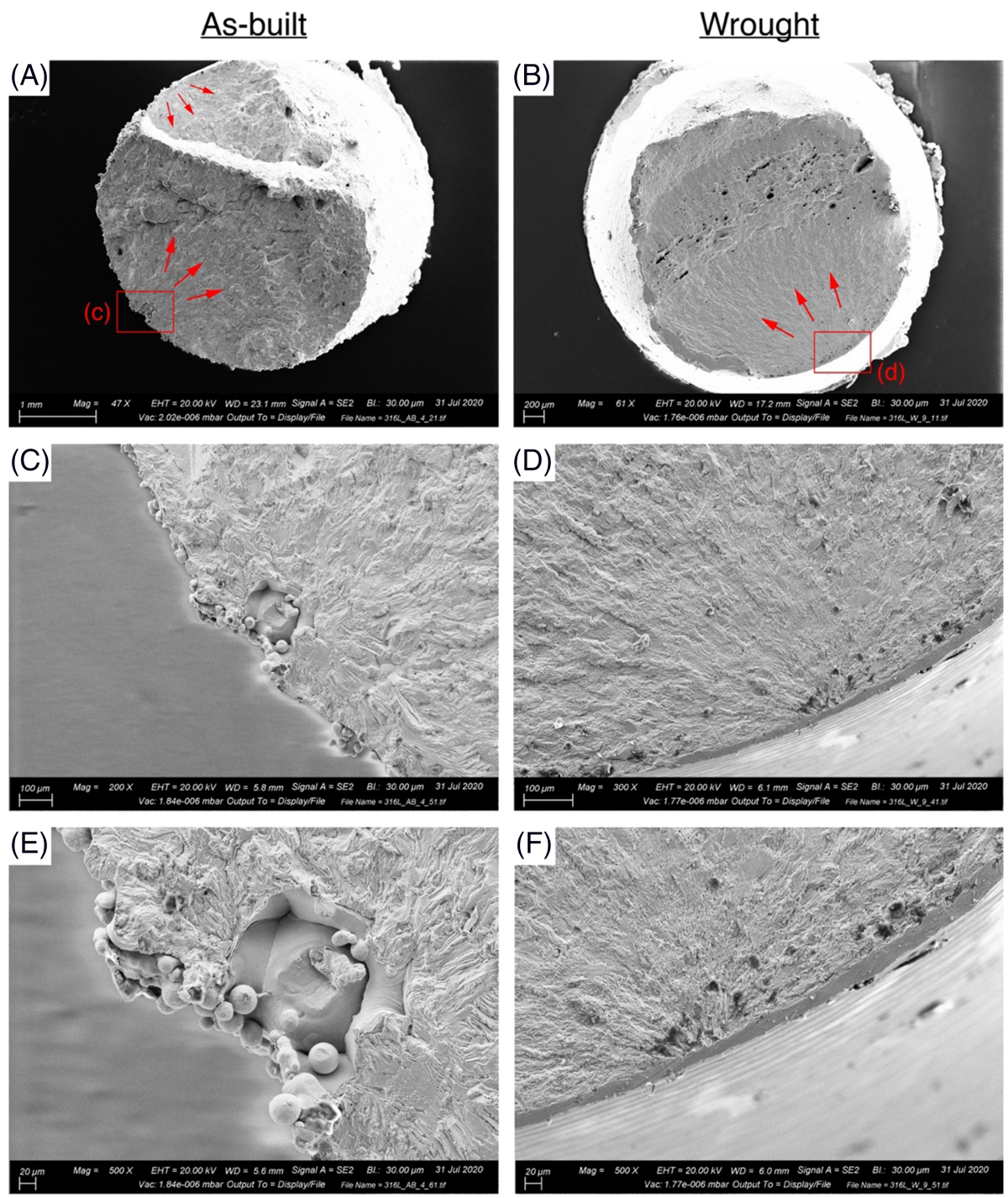

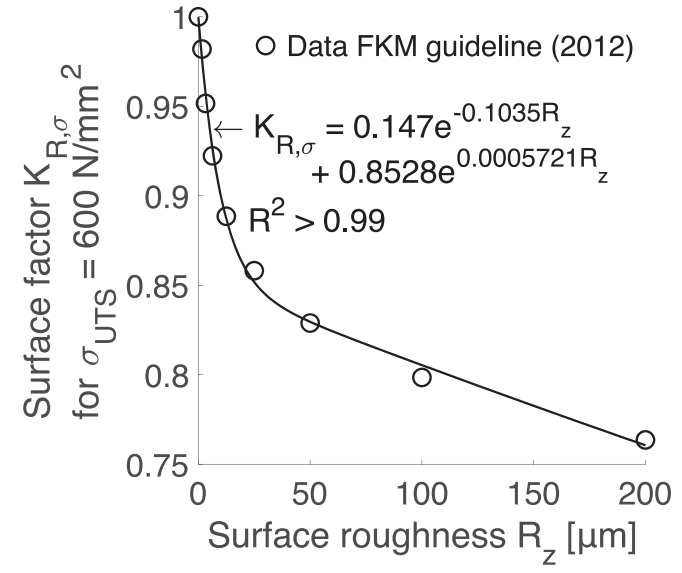

F I G U RE 12 Surface factor $K_{R, \sigma}$ for fatigue strength reduction based on data from the FKM guideline for steels with ultimate tensile strength $\sigma_{U T S}=600 \mathrm{MPa}^{47}$

\subsection{Assessment of mean-stress effect on fatigue strength}

Another aspect which is significantly influencing fatigue design of components is its mean stress sensitivity $M$ or in general the change of fatigue strength with cyclic mean stress. The mean stress sensitivity $M$ is defined by the ratio of reference fatigue strength $\Delta \sigma_{R}$ for pulsating (stress ratio $R=0)$ and alternating stress $(R=-1)$ with

$$
M=\frac{\Delta \sigma_{R}(R=-1)}{\Delta \sigma_{R}(R=0)}-1
$$

and typically decreases with increasing (tensile) mean stress. Similar to the reduction factor for surface roughness, the mean stress sensitivity $M$ can be estimated 
based on guidelines like the FKM guideline ${ }^{47}$ or when available from databases. Many production processes result in residual stresses that alter the stress state in a component or specimen. Just like welding, PBF-LB/M and other AM processes cause tensile residual stresses that reduce the fatigue strength. This is related to a superposition of external and residual stresses and thereby a higher mean stress; however, high external stresses can relax residual stresses. As the residual stress state and possible relaxation of residual stresses are unknown for the PBF-LB/M 316L specimens, additional tests with a stress ratio $R=-1$ have been performed. The results of these tests are presented in Figure 13. Additionally, the results are summarized in Table 4 with results for $R=0$ and showed as a comparison in Figure 14.

Similar to the tests performed under pulsating loading $(R=0)$, a large difference is observed between the as-built $\mathrm{PBF}-\mathrm{LB} / \mathrm{M}$ and wrought material specimens. Interesting to observe, however, the slope of the as-built $\mathrm{PBF}-\mathrm{LB} / \mathrm{M}$ is steeper for $R=-1$ than for $R=0$, while the opposite is true for the wrought material. This effect can be related to residual stresses in the PBF-LB/M specimens and is known from tests of welded specimens at different stress ratios; see Friedrich. ${ }^{50}$ Furthermore, the shallow slope of the wrought material $S-N$ curve led to a large number of run-outs for $R=-1$. A common way of presenting fatigue test results for different stress ratios is the Haigh diagram. Here, the mean stress sensitivity $M$ is defined as the mean slope of the line $\Delta \sigma_{R}(R)$. The Haigh diagrams for the as-built PBF-LB/M and wrought material specimens are presented in Figure 15 with results for $N=10^{5}$ and $N=2 \times 10^{6}$ cycles according to ASTM E468-18. ${ }^{51}$ In addition, lines with constant stress ratio $R$ and stress limits corresponding to yield and ultimate tensile strength $\left(\sigma_{Y S}\right.$ and $\left.\sigma_{U T S}\right)$ are included for the wrought material, which were obtained from the tensile tests presented in Figure 8.

First of all, a clear difference in mean stress sensitivity $M$ is apparent from Figure 15 as well as the difference in fatigue strength between PBF-LB/M and wrought material. While the fatigue strength of the wrought material is exceeding the yield strength $\sigma_{Y S}$ of the wrought material, it was not included in Figure 15A as the fatigue strength is only about half of the yield strength, even at $N=10^{5}$.

Due to the difference in slope exponent $k$ of the wrought material, the fatigue strength $\Delta \sigma_{R}(R=-1)$ is closer at $N=10^{5}$ than at $N=2 \times 10^{6}$ cycles. The fatigue strength (for $R=0$ ) at $N=10^{5}$ is indeed only slightly below the ultimate tensile strength $\sigma_{U T S}$. Interestingly, the $\Delta \sigma_{R}(R)$ line for the as-built specimens and $N=2 \times 10^{6}$ cycles is almost horizontal, which is clearly related to residual stresses from the production process. At higher applied loading, a relaxation of residual stresses has probably occurred, which led to a $\Delta \sigma_{R}(R)$ line for $N=10^{5}$ that looks similar to those of wrought material. In fact, the line for $N=2 \times 10^{6}$ cycles has a positive slope. This is probably related to statistical uncertainty. Furthermore, the approximately horizontal $\Delta \sigma_{R}(R)$ line and the relaxation of tensile residual stresses below half the yield strength of the material are a sign for very high residual stresses. This effect is typically observed for welded joints with tensile residual stresses reaching almost the yield strength level. The calculated mean stress sensitivities are summarized in Table 5 .

To assess the experimentally obtained result, the mean stress sensitivity of the wrought material is assessed using an empirical formula given by the FKM guideline. ${ }^{47}$
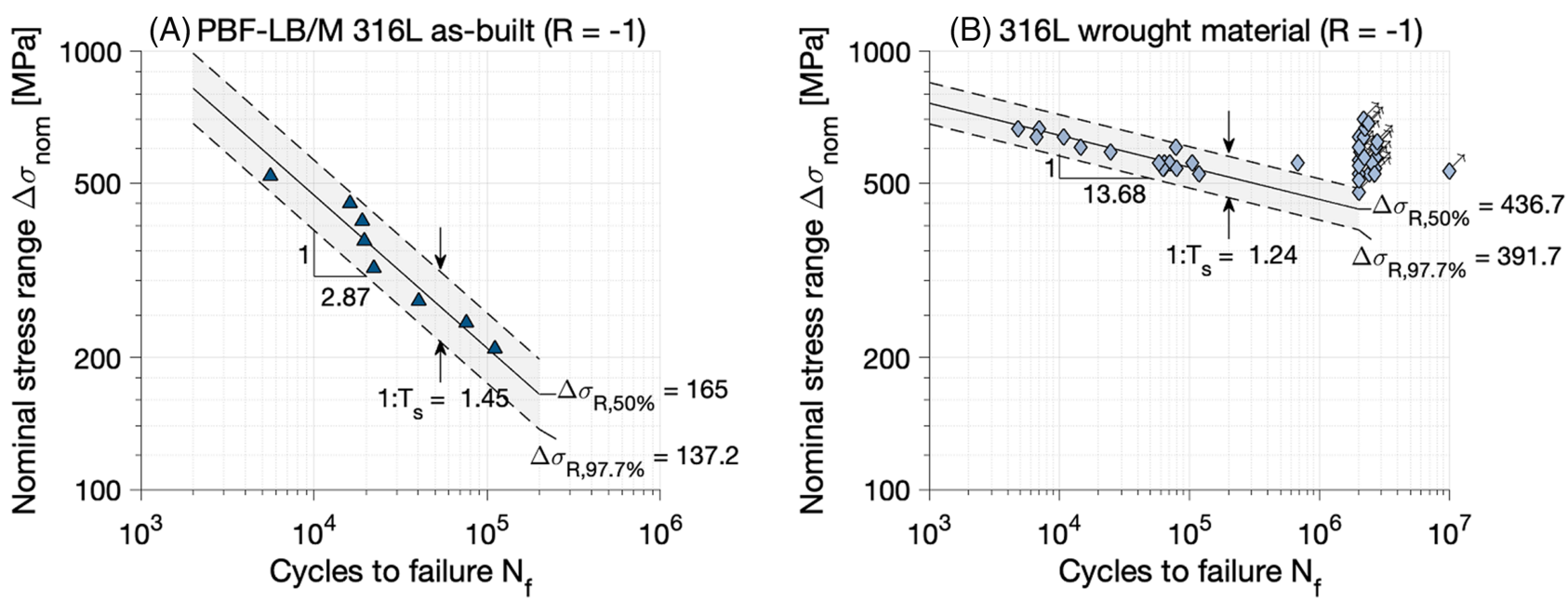

F I G U RE $13 S-N$ curves of PBF-LB/M 316L specimen in as-built state (A) and for wrought material (B) obtained from test with a stress ratio of $R=-1$ [Colour figure can be viewed at wileyonlinelibrary.com] 
TA B LE 4 Fatigue test results with calculated mean and characteristic fatigue strength in MPa evaluated at $N=2 \cdot 10^{6}$

\begin{tabular}{|c|c|c|c|c|c|}
\hline Test series & $R$-ratio $R$ & $\begin{array}{l}\text { Slope } \\
\text { exponent } k\end{array}$ & $\begin{array}{l}\text { Mean fatigue strength } \\
\Delta \sigma_{R, 50 \%}\left(P_{s}=50.0 \%\right)\end{array}$ & $\begin{array}{l}\text { Characteristic fatigue strength } \\
\Delta \sigma_{R, 97.7 \%}\left(P_{S}=97.7 \%\right)\end{array}$ & $\begin{array}{l}\text { Scatter } \\
\text { ratio } 1 / T_{s}\end{array}$ \\
\hline As-built & 0 & 3.67 & 177.0 & 158.9 & 1.24 \\
\hline Heat-treated & 0 & 4.04 & 208.0 & 186.1 & 1.25 \\
\hline $\begin{array}{l}\text { Machined \& } \\
\text { heat-treated }\end{array}$ & 0 & 9.27 & 389.9 & 350.0 & 1.24 \\
\hline \multirow[t]{2}{*}{ Wrought } & 0 & 7.14 & 348.4 & 281.5 & 1.53 \\
\hline & -1 & 13.68 & 436.7 & 391.7 & 1.24 \\
\hline
\end{tabular}
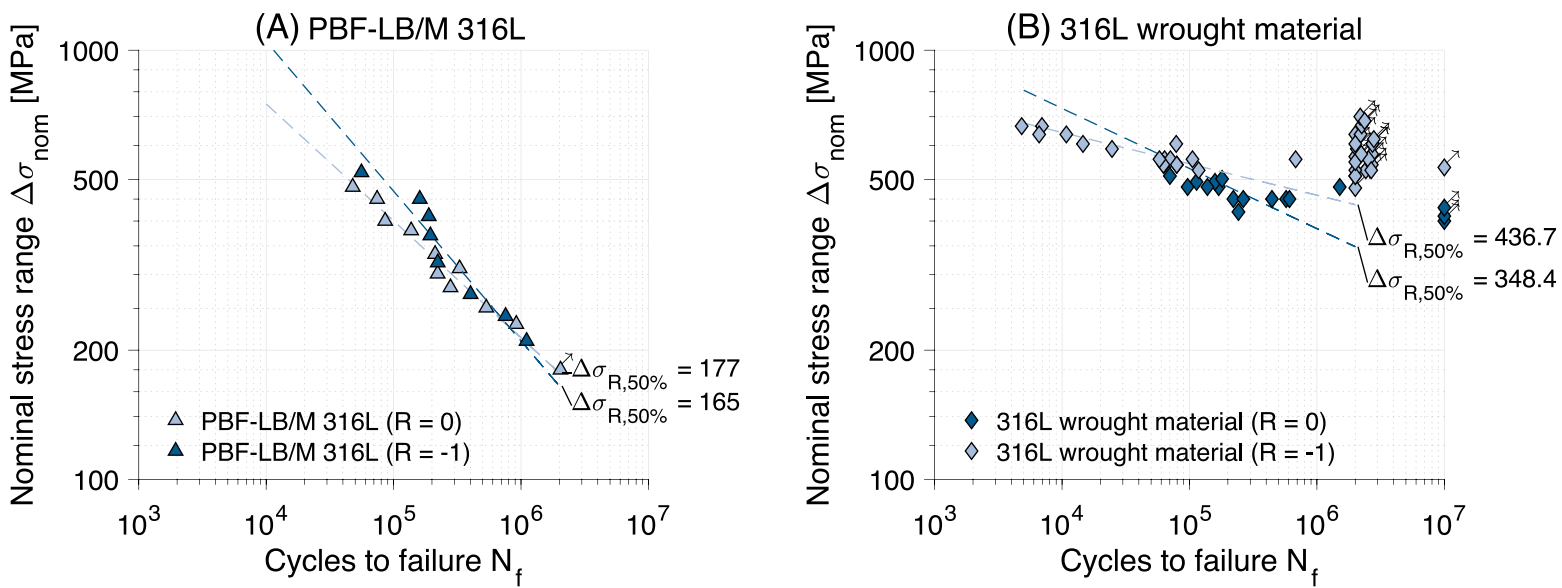

F I G U R E 14 Comparison of $S-N$ curves for stress ratios $R=-1$ and $R=0$ of PBF-LB/M 316L specimen in as-built state (A) and for wrought material (B) [Colour figure can be viewed at wileyonlinelibrary.com]

F I G URE 15 Haigh diagrams presenting the mean and range of fatigue strength (indicated by vertical lines for $2.3 \%$ and $97.7 \%$ survival probability) of PBF-LB/M 316 in as-built state (A) and $316 \mathrm{~L}$ wrought material (B) [Colour figure can be viewed at wileyonlinelibrary.com]
(A) PBF-LB/M 316L as-built

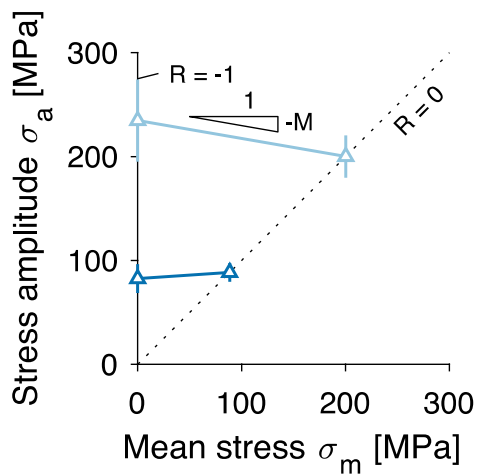

(B) $316 \mathrm{~L}$ wrought material

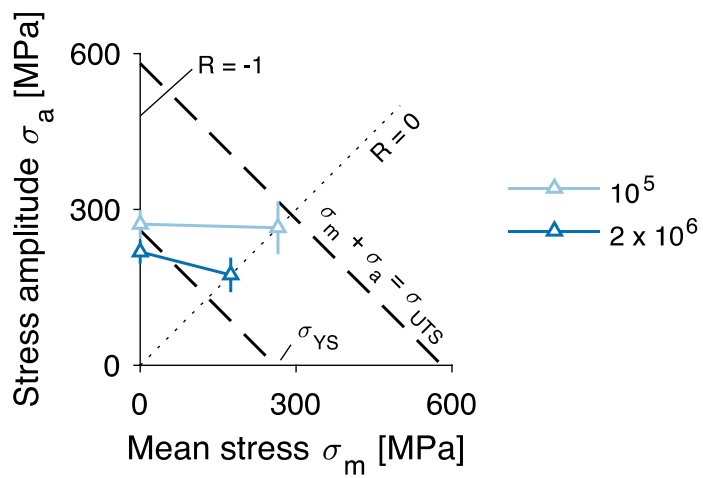

$$
M=a_{M} \cdot 10^{-3} \cdot \sigma_{U T S}+b_{M} ; \text { for } \sigma_{U T S} \operatorname{in}[\mathrm{MPa}]
$$

Here, $a_{M}=0.35$ and $b_{M}=-0.1$ are constants for steels including stainless steels. Inserting the ultimate tensile strength $\sigma_{U T S}$ results in a mean stress sensitivity of $M=0.303$, which is higher than the observed result. The FKM guidelines assume a fatigue limit at $N=10^{6}$ cycles for wrought material; however, this should not affect the estimated mean stress sensitivity significantly. Given the uncertainty of fatigue test results due to the shallow slope of the $S-N$ curves and the empirical nature of Equation 3, the difference between estimated and experimentally determined mean stress sensitivity is satisfactory. 
T A B L E 5 Experimentally determined mean stress sensitivity $M$ of as-built PBF-LB/M and wrought 316L

\begin{tabular}{lll} 
& \multicolumn{2}{c}{ Mean stress sensitivity $\boldsymbol{M}$} \\
\cline { 2 - 3 } Cycles $\boldsymbol{N}$ & As-built PBF-LB/M & Wrought material \\
\hline $10^{5}$ & 0.173 & 0.026 \\
$2 \times 10^{6}$ & -0.068 & 0.253 \\
\hline
\end{tabular}

\section{5 | DISCUSSION}

The experimental tests confirmed that the proposed postprocessing routes on PBF-LB/M 316L stainless steel components significantly improve fatigue strength up to the level of wrought material. After heat treatment, the fatigue strength increased only by $17.5 \%$ compared to the as-built state; however, further machining of the specimens improved the fatigue strength by an additional $87 \%$. In total, a combined fatigue strength improvement of $120 \%$ was obtained after both post-treatment processes. At this stage, a fatigue strength on par with that of wrought material was achieved. This confirms findings of recent studies on surface treatment of AM parts. Afkhami et al., ${ }^{34}$ for example, observed an improvement of $85 \%$ between as-built and machined 316L in vertical build direction; however, the fatigue strength was lower for both processing stages. In another study, Schneller et al. ${ }^{18}$ measured an improvement of $190 \%$ between asbuilt to machined AlSi10Mg specimens. Similarly, Sarkar et al. ${ }^{32}$ found an increase in fatigue strength of approximately $100 \%$ and $120 \%$, respectively, by electropolishing and rescanning of the surface for 15-5 PH steel. Compared with the results of Elangeswaran et al., ${ }^{21}$ the fatigue strength of $316 \mathrm{~L}$ was improved not only by machining but also by heat treatment. They observed a significant improvement of more than $100 \%$ after machining but almost no change due to heat treatment. This could be related to the lower heat treatment temperature of $470^{\circ} \mathrm{C}$ and a slight coarsening of the cellular solidification morphology in their specimens. In a number of other investigations, positive effects of heat treatment were observed for temperatures between $600^{\circ} \mathrm{C}$ and $650^{\circ} \mathrm{C}^{25-27}$ Again, this highlights the simplicity of improving the fatigue strength of AM parts by means of machining compared to other post-treatment methods, which is related to the removal of severe process-related defects at and close to the surface of AM parts and to a smaller extent due to the reduction in surface roughness and relaxation of tensile residual stresses. The majority of defects, as well as the largest defects, were mainly within $250 \mu \mathrm{m}$ from the surface; hence, the reason machining is so effective. For the applied scan strategy, this corresponds to four scan lines to sufficiently remove subsurface defects. Unsurprisingly, the highest improvement was observed for a combination of post-treatment techniques that improved the surface quality and altered process-related tensile residual stresses in both this study and others, cf. Elangeswaran et al. and Afkhami et al. ${ }^{21,34}$

Comparing the $S-N$ curve exponents of the tests performed at $R=0$, it becomes clear that fatigue life in asbuilt ( $k=3.67)$ and heat-treated $(k=4.04)$ state is dominated by fatigue crack propagation, while the machined and wrought material specimens are characterized by long crack initiation phases. Thus, they show a shallower slope with $k=9.27$ and $k=7.14$, respectively. Large defects close to the surface are consequently responsible not only for the total fatigue life but also for the relation between fatigue crack initiation and propagation.

If the surface of AM parts is machined, crack initiation locations sometimes shift to internal defects. Such a crack initiating transition was also observed in a recent study by Solberg et al. ${ }^{46}$ for high loads close to the low-cycle fatigue regime and the same steel. This was, however, not the case in this study. Comparing the scanning electron microscope figures and micrographs, the defect sizes of the specimens tested by Solberg et al. ${ }^{46}$ appear much larger. This is surprising as the mean fatigue strength at $N=2 \times 10^{6}$ cycles vary by only $8.5 \%$.

Due to process-related tensile residual stresses, a clear difference in mean stress sensitivity $M$ between as-built $\mathrm{PBF}-\mathrm{LB} / \mathrm{M}$ and wrought material is apparent from the additional test with a stress ratio $R=-1$ and the constructed Haigh diagram. From this diagram, a different mean stress sensitivity was determined for $N=10^{5}$ and $N=2 \times 10^{6}$ cycles for both materials. While this effect is related to the change in slope exponent of the wrought material, it is probably related to relaxation of residual stresses for the PBF-LB/M material. At higher applied loading, a relaxation of residual stresses has led to a $\Delta \sigma_{R}(R)$ line for $N=10^{5}$ that looks similar to those of wrought material. For low applied loading, the fatigue strength is almost identical for both stress ratios, and thus, the $\Delta \sigma_{R}(R)$ line for the as-built specimens is almost horizontal. Furthermore, the fatigue strength of the wrought material is exceeding the yield strength $\sigma_{Y S}$ of the wrought material, and it is only about half of the yield strength at $N=10^{5}$. In fact, the fatigue strength of the wrought material for $R=0$ and $N=10^{5}$ is only slightly below the ultimate tensile strength $\sigma_{U T S}$.

Comparing tensile tests of PBF-LB/M and wrought material specimens extracted in different build and rolling direction, results from other studies were confirmed and extended. The PBF-LB/M specimens are characterized by a higher yield, higher ultimate tensile strength, and lower ductility in all three build directions, 
while the wrought material is characterized by a low yield strength and high ductility; this is typical for annealed 316L plates, cf. previous studies. ${ }^{15,42-44}$ This behavior is attributed to the Hall-Petch relationship and to the difference in microstructure. ${ }^{21}$

\section{6 | CONCLUSIONS AND FUTURE WORK}

The fatigue strength of additively manufactured components produced by PBF-LB/M depends on factors such as the microstructure, surface roughness, residual stresses, and above all, porosity and other defects. The aim of this study was to investigate the influence of surface roughness in relation to the accumulation of pores and defects in the surface layer of additively manufactured components. For this purpose, state-of-the-art of post-treatment processes for AM components was presented using the example of 316L stainless steel (1.4404), and the possible increase in fatigue strength as a result of different processing routes was comparatively investigated by fatigue testing including the as-built condition, heat treatment, and machining. Finally, the results were compared with wrought material and the effect of cyclic mean stress assessed by means of a Haigh diagram.

Post-treatment of additively manufactured materials enables a significant increase in fatigue strength. Conversely, the as-built state has low fatigue strength due to overlapping negative effects from the manufacturing process. Based on the investigations carried out and a literature evaluation of various post-treatment processes, the following conclusions are drawn:

- The fatigue strength of as-built materials is significantly reduced by the surface roughness, tensile residual stresses, and process-induced defects. Pores and LOF defects are highly concentrated near to the surface. Also, non- or partially fused powder particles and irregular melt pool surfaces lead to high surface roughness.

- Based on an experimental assessment of the three influencing factors (residual stresses, surface roughness, and defects) that cause low fatigue strength, it is concluded that defects in the surface layer have the highest effect.

- Possibilities for improving the fatigue strength of additive materials include surface post-treatment and residual stress-reducing or compressive stress-inducing techniques. Of these, machining has proven to be an easy and reliable post-treatment processes of stainless steels. In this study, increases in fatigue strength of PBF-LB/M 316L stainless steel of $87 \%$ and $17.5 \%$ compared to the as-built condition were determined for machining and heat treatment, respectively.

- High improvement by machining is effective as the majority of defects, and the largest defects, were mainly within $250 \mu \mathrm{m}$ of the surface. For the applied scan strategy, this corresponds to four scan lines to sufficiently remove subsurface defects.

- The mean stress sensitivity $M$ between as-built PBF$\mathrm{LB} / \mathrm{M}$ and wrought material is found to be highly affected by the assessed number of cycles to failure. While this effect is related to the change in slope exponent of the wrought material with applied stress ratio, it is likely related to relaxation of residual stresses for the PBF-LB/M material.

For future work on hybrid manufactured PBF-LB/M stainless steels and industrial applications, the authors recommend the application of local fatigue assessment methods either based on short fatigue crack growth models ${ }^{52}$ or effective stress-based concepts in combination with models to account for production-related defects, for example, Schneller et al. ${ }^{53,54}$ Both are in theory capable of accounting for variations of surface quality, notch shapes, and defects that cause crack initiation from surfaces. Additionally, measurements of residual stress states before and after different heattreatment temperatures might yield a better understanding of residual stress relief in PBF-LB/M stainless steels.

\section{ACKNOWLEDGMENT}

There is nobody acknowledged for this study.

Open access funding enabled and organized by Projekt DEAL.

\section{AUTHOR CONTRIBUTIONS}

M. B. and S. E. performed the conceptualization and methodology. M. B., I. K., C. W., and R. E. W. performed the investigation. E. M. and S. S. performed the specimen fabrication and characterization. M. B., S. S., A. T., and R. E. W. wrote the manuscript. S. E. reviewed the manuscript. S. B. provided funding for CT scans.

\section{DATA AVAILABILITY STATEMENT}

The data that support the findings of this study are available from the corresponding author upon reasonable request.

\section{NOMENCLATURE}

$\Delta \sigma_{n}, \Delta \sigma_{R} \quad$ nominal stress range and reference fatigue strength

$K_{R, \sigma} \quad$ surface factor for fatigue strength reduction

$K_{t} \quad$ stress concentration factor

$R^{2} \quad$ goodness-of-fit parameter 


\begin{tabular}{|c|c|}
\hline$R_{a}, R_{t}$ & $\begin{array}{l}\text { arithmetic mean roughness and maximum } \\
\text { roughness }\end{array}$ \\
\hline$R_{z}$ & $\begin{array}{l}\text { maximum peak to valley height of five } \\
\text { subprofiles }\end{array}$ \\
\hline$T_{\sigma}$ & scatter range \\
\hline$a_{M}, b_{M}$ & $\begin{array}{l}\text { constants of mean stress sensitivity } \\
\text { estimation }\end{array}$ \\
\hline$\sigma_{Y S}, \sigma_{U T S}$ & yield and ultimate tensile strength \\
\hline$\sigma_{a}, \sigma_{m}$ & stress amplitude and cyclic mean stress \\
\hline$\epsilon_{f}$ & fracture strain \\
\hline AM & additive manufacturing \\
\hline CT & computed tomography \\
\hline PBF-LB/M & laser-based powder bed fusion of metals \\
\hline$E$ & Young's modulus \\
\hline$M$ & mean stress sensitivity \\
\hline$N, N_{f}$ & cycles and cycles to failure \\
\hline$R$ & stress ratio \\
\hline$k$ & inverse slope exponent \\
\hline
\end{tabular}

\section{ORCID}

Moritz Braun (1) https://orcid.org/0000-0001-9266-1698 Aliakbar Taghipour (D) https://orcid.org/0000-0002-42108488

Sören Ehlers (1D https://orcid.org/0000-0001-5698-9354

\section{REFERENCES}

1. Gebler M, Schoot Uiterkamp AJM, Visser C. A global sustainability perspective on 3D printing technologies. Energy Policy. 2014;74:158-167.

2. Stern F, Kleinhorst J, Tenkamp J, Walther F. Investigation of the anisotropic cyclic damage behavior of selective laser melted AISI 316L stainless steel. Fatigue Fract Eng M. 2019;42(11): 2422-2430.

3. Benedetti M, Fontanari V, Bandini M, Zanini F, Carmignato S. Low- and high-cycle fatigue resistance of Ti-6Al-4V ELI additively manufactured via selective laser melting: Mean stress and defect sensitivity. Int J Fatigue. 2018;107:96-109.

4. Masuo H, Tanaka Y, Morokoshi S, et al. Influence of defects, surface roughness and HIP on the fatigue strength of Ti-6Al-4V manufactured by additive manufacturing. Int J Fatigue. 2018; 117:163-179.

5. Braun M, Hellberg S, Kryukov I, et al. Untersuchung der Schwingfestigkeit hybrid additiv und subtraktiv gefertigter Proben aus AISI 316L. 5. Tagung Additiv gefertigte Bauteile und Strukturen. Berlin, Germany; 2020:4.-5.11.

6. Lv S, Tao H, Hong Y, et al. Surface treatment and corrosion behavior of 316L stainless steel fabricated by selective laser melting. Materials Research Express. 2019;6(10):106518.

7. Teo AQA, Yan L, Chaudhari A, O'Neill GK. Post-processing and surface characterization of additively manufactured stainless steel 316L lattice: implications for biomedical use. Materials (Basel). 2021;14(6):1376.

8. Cortina M, Arrizubieta JI, Ruiz JE, Ukar E, Lamikiz A. Latest developments in industrial hybrid machine tools that combine additive and subtractive operations. Materials (Basel). 2018; 11(12):2583.
9. Garb C, Leitner M, Tauscher M, Weidt M, Brunner R. Statistical analysis of micropore size distributions in Al-Si castings evaluated by X-ray computed tomography. Int J Mater Res. 2018;109(10):889-899.

10. Shirani M, Härkegård G. Damage tolerant design of cast components based on defects detected by 3D X-ray computed tomography. Int J Fatigue. 2012;41:188-198.

11. Falkowska A, Seweryn A, Tomczyk A. Fatigue life and strength of 316L sintered steel of varying porosity. Int J Fatigue. 2018; 111:161-176.

12. Romano S, Brandão A, Gumpinger J, Gschweitl $\mathrm{M}$, Beretta S. Qualification of AM parts: extreme value statistics applied to tomographic measurements. Mater Design. 2017; 131:32-48.

13. Andreau O, Pessard E, Koutiri I, et al. A competition between the contour and hatching zones on the high cycle fatigue behaviour of a 316L stainless steel: analyzed using X-ray computed tomography. Mater Sci Eng a. 2019;757:146-159.

14. Zhao C, Parab ND, Li X, et al. Critical instability at moving keyhole tip generates porosity in laser melting. Science. 2020; 370(6520):1080-1086.

15. Zerbst U, Hilgenberg K. Damage development and damage tolerance of structures manufactured by selective laser meltinga review. Procedia Struct Integ. 2017;7:141-148.

16. Meier H, Haberland C. Experimental studies on selective laser melting of metallic parts. Materialwissenschaft und Werkstofftechnik. 2008;39(9):665-670.

17. Shiomi M, Osakada K, Nakamura K, Yamashita T, Abe F. Residual stress within metallic model made by selective laser melting process. CIRP Annals. 2004;53(1):195-198.

18. Schneller W, Leitner M, Springer S, Beter F, Grün F. Influencing factors on the fatigue strength of selectively laser melted structures. Procedia Struct Integ. 2019;19:556-565.

19. Pegues JW, Shao S, Shamsaei N, et al. Fatigue of additive manufactured Ti-6Al-4V, Part I: the effects of powder feedstock, manufacturing, and post-process conditions on the resulting microstructure and defects. Int J Fatigue. 2020;132:105358.

20. Cutolo A, Elangeswaran C, de Formanoir C, Muralidharan GK, van Hooreweder B. Effect of heat treatments on fatigue properties of $\mathrm{Ti}-6 \mathrm{Al}-4 \mathrm{~V}$ and $316 \mathrm{~L}$ produced by laser powder bed fusion in as-built surface condition. In: TMS 2019 148th Annual Meeting \& Exhibition Supplemental Proceedings; 2019: 395-405.

21. Elangeswaran C, Cutolo A, Muralidharan GK, et al. Effect of post-treatments on the fatigue behaviour of $316 \mathrm{~L}$ stainless steel manufactured by laser powder bed fusion. Int J Fatigue. 2019; 123:31-39.

22. Leuders $\mathrm{S}$, Lieneke $\mathrm{T}$, Lammers $\mathrm{S}$, Tröster $\mathrm{T}$, Niendorf $\mathrm{T}$. On the fatigue properties of metals manufactured by selective laser melting-the role of ductility. J Mater Res. 2014;29(17): 1911-1919.

23. Riemer A, Leuders S, Thöne $M$, Richard HA, Tröster T, Niendorf T. On the fatigue crack growth behavior in $316 \mathrm{~L}$ stainless steel manufactured by selective laser melting. Eng Fract Mech. 2014;120:15-25.

24. Geenen K, Röttger A, Theisen W. Corrosion behavior of $316 \mathrm{~L}$ austenitic steel processed by selective laser melting, hot-isostatic pressing, and casting. Mater Corros. 2017;68(7):764-775.

25. Montero-Sistiaga M, Nardone S, Hautfenne C, Humbeeck J. Effect of heat treatment of 316L stainless steel produced by 
selective laser melting (SLM). In: Solid Freeform Fabrication Symposium; 2016/07/08-2016/07/10. Austin, Texas, USA; 2016.

26. Kamariah MSIN, Harun WSW, Khalil NZ, Ahmad F, Ismail $\mathrm{MH}$, Sharif S. Effect of heat treatment on mechanical properties and microstructure of selective laser melting 316L stainless steel. IOP Conf Sers: Mater Sci Eng. 2017;257:012021.

27. Tascioglu E, Karabulut Y, Kaynak Y. Influence of heat treatment temperature on the microstructural, mechanical, and wear behavior of 316L stainless steel fabricated by laser powder bed additive manufacturing. Int J Adv Manuf Technol. 2020; 107(5-6):1947-1956.

28. Fergani O, Bratli Wold A, Berto F, Brotan V, Bambach M. Study of the effect of heat treatment on fatigue crack growth behaviour of 316L stainless steel produced by selective laser melting. Fatigue Fract Eng M. 2018;41(5):1102-1119.

29. Hemmasian Ettefagh A, Guo S. Electrochemical behavior of AISI316L stainless steel parts produced by laser-based powder bed fusion process and the effect of post annealing process. Addit Manuf. 2018;22:153-156.

30. Poulin JR, Brailovski V, Terriault P. Long fatigue crack propagation behavior of Inconel 625 processed by laser powder bed fusion: Influence of build orientation and post-processing conditions. Int J Fatigue. 2018;116:634-647.

31. Scurria M, Möller B, Wagener R, Melz T. Effect of the surface finish on the cyclic behavior of additively manufactured AlSi10Mg. In: TMS 2019 148th Annual Meeting \& Exhibition Supplemental Proceedings; 2019:383-394.

32. Sarkar S, Kumar CS, Nath AK. Effects of different surface modifications on the fatigue life of selective laser melted 15-5 PH stainless steel. Mater Sci Eng a. 2019;762:138109.

33. Denti L, Bassoli E, Gatto A, Santecchia E, Mengucci P. Fatigue life and microstructure of additive manufactured Ti6Al4V after different finishing processes. Mater Sci Eng a. 2019;755:1-9.

34. Afkhami S, Dabiri M, Piili H, Björk T. Effects of manufacturing parameters and mechanical post-processing on stainless steel 316L processed by laser powder bed fusion. Mater Sci Eng a. 2021;802:140660.

35. Solberg K, Berto F. What is going on with fatigue of additively manufactured metals? Mater Design Process Commun. 2019; 1(5):e84.

36. Han YS, Xu B, Zhao L, Xie YM. Topology optimization of continuum structures under hybrid additive-subtractive manufacturing constraints. Struct Multidiscip Optim. 2019; 60(6):2571-2595.

37. ASTM E466-15. Standard practice for conducting force controlled constant amplitude axial fatigue tests of metallic materials. West Conshohocken, PA; 2015.

38. Pilkey WD, Pilkey DF. Peterson's Stress Concentration Factors. John Wiley \& Sons; 2008.

39. Yadollahi A, Shamsaei N. Additive manufacturing of fatigue resistant materials: Challenges and opportunities. Int J Fatigue. 2017;98:14-31.

40. Braun M, Hensel J, Song S, Ehlers S. Fatigue strength of normal and high strength steel joints improved by weld profiling. Engineering Structures. 2021. submitted for publication

41. McDavid J. Herstellung von AM Proben aus der Legierung 1.4404 durch das SLM-Verfahren und Analyse der Wechselwirkung zwischen Probenorientierung im Druckraum mit den mechanisch-technologischen Eigenschaften [Master thesis]. University of Applied Science Hamburg, Institute of Materials Science and Joining Technology; 2019.

42. Wood P, Libura T, Kowalewski ZL, Williams G, Serjouei A. Influences of horizontal and vertical build orientations and post-fabrication processes on the fatigue behavior of stainless steel 316L produced by selective laser melting. Materials (Basel). 2019;12(24).

43. Hong Y, Zhou C, Zheng Y, et al. Formation of strain-induced martensite in selective laser melting austenitic stainless steel. Materials Science and Engineering: A. 2019;740-741:420-426.

44. Carlton HD, Haboub A, Gallegos GF, Parkinson DY, MacDowell AA. Damage evolution and failure mechanisms in additively manufactured stainless steel. Mater Sci Eng a. 2016; 651:406-414.

45. Radaj D. Design and Analysis of Fatigue Resistant Welded Structures. Cambridge: Woodhead Publishing; 1990.

46. Solberg K, Guan S, Razavi SMJ, Welo T, Chan KC, Berto F. Fatigue of additively manufactured 316L stainless steel: the influence of porosity and surface roughness. Fatigue Fract Eng M. 2019;42(9):2043-2052.

47. FKM-Richtlinie. Rechnerischer Festigkeitsnachweis für Maschinenbauteile aus Stahl, Eisenguss- und Aluminiumwerkstoffen. VDMA-Verlag, Frankfurt/Main; 2012.

48. EN ISO 4288. 1997: Geometrical product specifications (GPS) surface texture: profile method - rules and procedures for the assessment of surface texture. Brussels, BE.

49. von Bock und Polach RUF, Kahl A, Braun M, von Selle H, Ehlers S. Analysis of governing parameters on the fatigue life of thermal cut edges. In: International Conference on Ships and Offshore Structures ICSOS 2019; 04-08 November 2019. USA: Cape Carnival; 2019.

50. Friedrich N. Experimental investigation on the influence of welding residual stresses on fatigue for two different weld geometries. Fatigue Fract Eng M. 2020;43(11):2715-2730.

51. ASTM E468-18. Standard practice for presentation of constant amplitude fatigue test results for metallic materials. West Conshohocken, PA, 2018.

52. Bergant M, Werner T, Madia M, Yawny A, Zerbst U. Short crack propagation analysis and fatigue strength assessment of additively manufactured materials: An application to AISI 316L. Int J Fatigue. 2021;151:106396.

53. Schneller W, Leitner M, Pomberger S, et al. Fatigue strength assessment of additively manufactured metallic structures considering bulk and surface layer characteristics. Addit Manuf. 2021;40:101930.

54. Schneller W, Leitner M, Leuders S, et al. Fatigue strength estimation methodology of additively manufactured metallic bulk material. Addit Manuf. 2021;39:101688.

How to cite this article: Braun $\mathrm{M}$, Mayer $\mathrm{E}$, Kryukov I, et al. Fatigue strength of PBF-LB/M and wrought 316L stainless steel: effect of posttreatment and cyclic mean stress. Fatigue Fract Eng Mater Struct. 2021;44(11):3077-3093. https://doi. org/10.1111/ffe.13552 